\title{
Review Article \\ Development of Magnetic Nanoparticles for Cancer Gene Therapy: A Comprehensive Review
}

\author{
Vladimir Mulens, ${ }^{1}$ María del Puerto Morales, ${ }^{2}$ and Domingo F. Barber ${ }^{1}$ \\ ${ }^{1}$ Department of Immunology and Oncology \& Nanobiomedicine Initiative, National Center for Biotechnology (CNB)/CSIC, \\ Darwin 3, Cantoblanco, 28049 Madrid, Spain \\ ${ }^{2}$ Department of Biomaterials and Bioinspired Materials, Institute of Materials Science of Madrid (ICMM)/CSIC, \\ Sor Juana Inés de la Cruz 3, Cantoblanco, 28049 Madrid, Spain
}

Correspondence should be addressed to Domingo F. Barber; dfbarber@cnb.csic.es

Received 10 July 2013; Accepted 13 August 2013

Academic Editors: M. R. Ferreira and N. R. Jana

Copyright ( $) 2013$ Vladimir Mulens et al. This is an open access article distributed under the Creative Commons Attribution License, which permits unrestricted use, distribution, and reproduction in any medium, provided the original work is properly cited.

\begin{abstract}
Since they were first proposed as nonviral transfection agents for their gene-carrying capacity, magnetic nanoparticles have been studied thoroughly, both in vitro and in vivo. Great effort has been made to manufacture biocompatible magnetic nanoparticles for use in the theragnosis of cancer and other diseases. Here we survey recent advances in the study of magnetic nanoparticles, as well as the polymers and other coating layers currently available for gene therapy, their synthesis, and bioconjugation processes. In addition, we review several gene therapy models based on magnetic nanoparticles.
\end{abstract}

\section{Introduction}

1.1. Cancer \& Current Therapy. Although huge efforts have led to advances in cancer treatment, this multifactorial and heterogeneous disease is still one of the major causes of death in the majority of countries [1-4]. Several factors influence the high death rate of cancer patients around the world, such as the genetic and phenotypic heterogeneity and the highly unstable genome of cancer cells, which ultimately leads to continuously emerging, nonheterogeneous cells from the tumor nest, and subsequent metastases [5].

Current cancer therapy encompasses a wide variety of treatments from systemic cytostatics to targeted therapy agents, most still in development phases, such as kinase inhibitors [6-9], antibodies [10, 11], small molecules, or celland antigen-based immunotherapies [12, 13]. Nevertheless, most approved therapeutics require systemic administration, which increases their toxicity and other clinical complications. One factor that eventually contributes to therapeutic toxicity is nonspecificity. Guidance of drugs to the desired tissue and specific target recognition are therefore major concerns faced by cancer researchers seeking less toxic side effects and improved efficiency of therapy.
Targeted strategies include ligand-receptor binding, antibody-antigen specificity, and some other forms of active targeting. For instance, several antibodies have been developed that are directed to specific tumor-associated antigens, either expressed uniquely by tumor cells or overexpressed compared with healthy tissue; this is the case of the HER2-specific antibody Herceptin [10], the VEGFspecific antibody Bevacizumab [11], and ganglioside-specific antibodies such as 14F7 [14].

Nanotechnology, and in particular a magnetic nanoparticle-based approach, is a promising tool for the guidance of therapeutic agents into tumor tissues.

1.2. Nanotechnology in Cancer Theragnosis. Use of nanotechnology is widespread in several fields of biomedicine due to its potential in controlled drug delivery systems [15, 16], for diagnostic agents [17] and biosensors [18], among other applications. The basis for their use in biomedicine centers on the combination of their distinctive physical properties, including their optical, electronic, and magnetic behaviors. These properties arise from the combination of two characteristics: a large surface area and the quantum confinement effect due to the nanoscale sizes. Nanoparticles 
are usually coated with polymers or other coating layers that could endow additional functions.

One promising physical property of nanosystems in cancer biomedicine is their magnetism, especially superparamagnetism [19]. Two physical parameters theoretically define magnetic materials, magnetization or magnetic polarization, and the applied magnetic field $(H)$. When materials show linear dependence between these two parameters as well as low maximum magnetization, they are classified as weak magnetic materials. In addition, these materials can be subdivided into paramagnetic and diamagnetic substances, depending on whether magnetization is positive or negative.

Strong magnetic materials differ from the above not only in their high magnetization but also in their complex behavior following exposure to an external magnetic field. This behavior is described by the hysteresis loop. Strong magnetic materials are classified as ferrimagnets, ferromagnets, and antiferromagnets, among others. There is a critical temperature value (Curie temperature and Neel temperature for ferrimagnets and antiferromagnets, resp.), below which magnetic polarization increases up to saturation. Saturation magnetization decreases as the temperature increases below these critical values. Ferromagnets show remanent magnetization when the external magnetic field is off. Above critical temperature, these materials become superparamagnetic, with a reversible magnetization curve (Figure 1) and zero magnetic moment when the magnetic field is removed; magnetic moments reach values more than 10 to 4 times larger than those for paramagnetics if an external magnetic field is applied.

Particles derived from the ferro/ferrimagnetic bulk state and nanosized to as small as 1 to $30 \mathrm{~nm}$ diameter, depending on the material, behave superparamagnetically [20]. Nanosystems in this state basically show linear dependence of magnetic susceptibility and applied magnetic field intensity, as paramagnets do, but almost constant magnetization once magnetic polarization is saturated. Superparamagnetic nanosystems show no hysteresis and negligible remanent magnetization.

Different areas or domains in which atoms are pinned in the same direction commonly form ferromagnetic materials. This phase separation is due to the gain of stability caused by a decrease in magnetostatic energy as new domains arise inside the bulk. The formation of new magnetic domains nonetheless requires a certain amount energy, which constrains the size resulting from the break-bulk. This is because the energy needed to form magnetic domains surpasses the magnetostatic energy, making the process infeasible. Below a certain size, a single-domain structure thus prevails. Therefore, magnetic nanoparticles due to their size show a single domain structure.

Magnetic nanoparticles are applied in cancer theragnosis as contrast agents [21-23], for example, for magnetic resonance images (MRIs). Superparamagnetic iron oxide nanoparticles (SPIONs) must nonetheless be able to evade the immune system to slow down their clearance from the bloodstream and other biological fluids. SPIONs are eliminated from the circulation mostly through the reticuloendothelial system (RES) and renal clearance mechanisms [24-29].

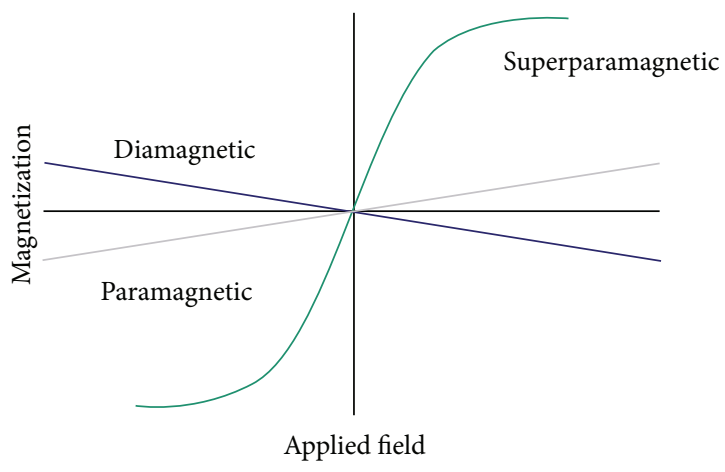

FIGURE 1: Magnetic behavior of materials as determined by relationship between magnetization and applied magnetic field.

One factor that influences nanoparticle clearance is their hydrodynamic size. In general, particles between 10 and $100 \mathrm{~nm}$ have the longest circulation time [30]; by contrast, $200 \mathrm{~nm}$ diameter particles tend to be eliminated by the RES, and those with diameters $<10 \mathrm{~nm}$ are removed mainly by renal filtration.

Nanoparticle size also affects their ability to extravasate from the bloodstream into tumor tissues, through the socalled transcytosis process [31, 32]. This process depends on particle size, with an upper limit of $\sim 150 \mathrm{~nm}$. Another important factor is the chemical nature of the nanoparticle surface [33]. For instance, positive surface charge allows nanoparticles to adhere nonspecifically to cell membranes whilst negative surface charge leads to adsorption of plasma proteins, thus increasing uptake and clearance via the RES $[34,35]$. Furthermore, plasma protein interaction with negatively and positively charged nanoparticles induces different biological responses [36]. Hydrophilic and neutral surfaces endow nanoparticles with enhanced stealth, as they interact less with blood proteins. The rationale and evidence for the distinct factors that affect nanoparticle-biological interfaces have been reviewed elsewhere [37].

Passive SPION-based cancer theragnosis relies on specific features of the tumor microenvironment. These characteristics allow nanoparticles to permeate tumor tissue without extra active forces, though nanoparticle concentration can be increased if such forces are used. The disorganized, leaky, damaged vasculature of tumor tissue due to accelerated angiogenesis facilitates SPION permeation of the tumor microenvironment [38]. Once inside tumor tissue, nanoparticles are retained due to the poorly developed lymphatic vessels; this phenomenon is known as the enhanced permeability and retention effect (EPR) (Figure 2). This high grade of retention in tumor tissues allows most nanoparticles to be taken up by tumor and stromal cells, including immune cells. According to some reports, upper limits for macromolecule size to show the EPR effect could be up to $1-2 \mu \mathrm{m}$, as for Lactobacillus sp. [39], which accumulate preferentially in tumor tissues.

Modification of the tumor microenvironment is indeed another way to achieve better nanoparticle uptake by malignant cells. These approaches intend to increase the EPR effect 


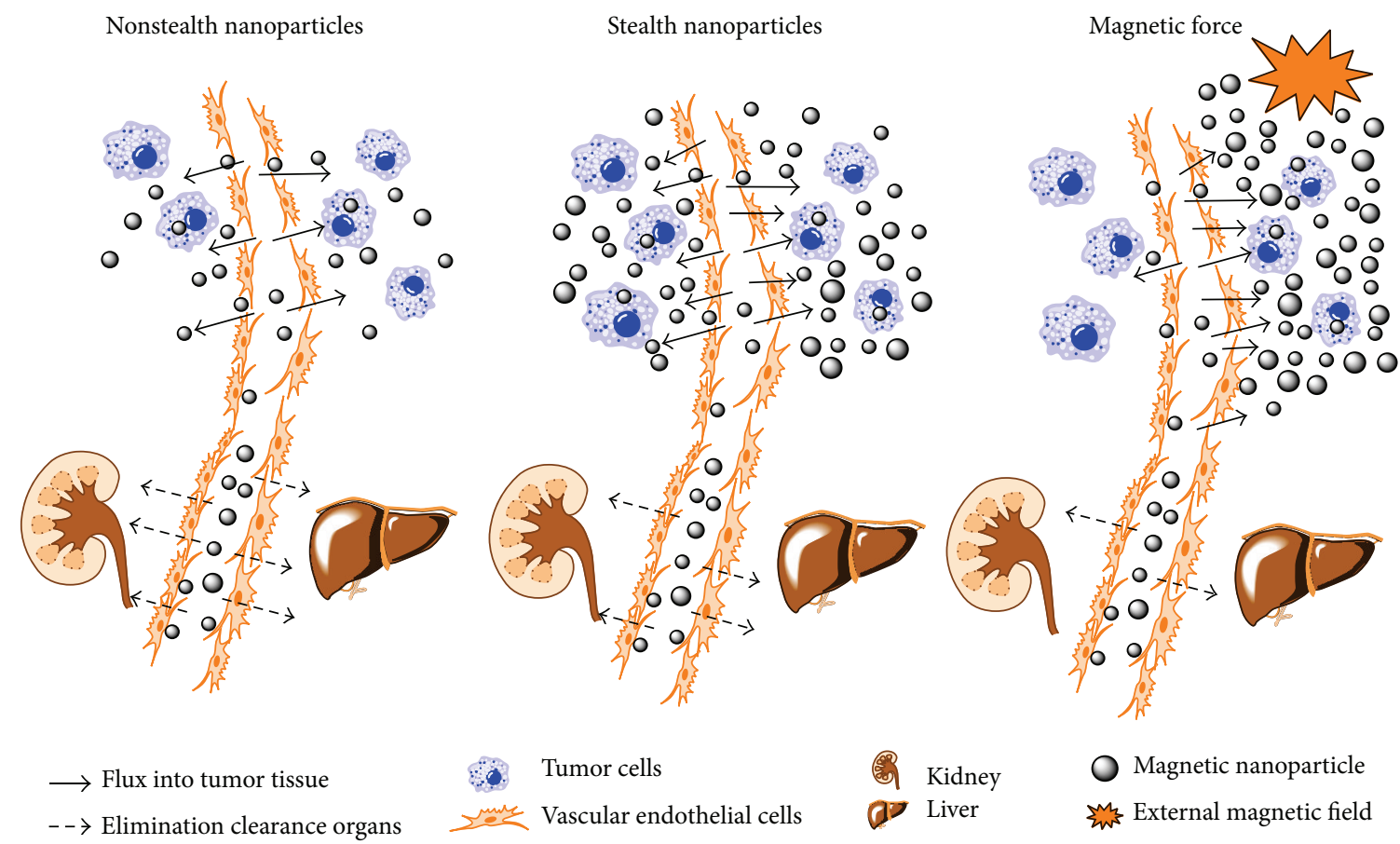

FIGURE 2: The enhanced permeability retention effect (EPR) in a scenario of magnetic nanoparticle-based cancer therapy. Due to the weak tumor vasculature, nanoparticles are able to permeate the tumor microenvironment, although clearance organs and the reticuloendothelial system (RES) eliminate most. Polymers/moieties endow nanoparticles with stealth and specificity and thus with RES-evading capacity; nanoparticle concentration in tumor tissue consequently increases. This nanoparticle accumulation in targeted tissue further increases as an external magnetic field is applied.

inherent to solid tumors; for instance, application of a single 15 Gy-radiation dose in a syngeneic mouse breast tumor model doubled the accumulation of iron oxide nanoparticles in tumor tissue [40]. This effect is associated with decreased interstitial pressure and the subsequent increase in vascular permeability and thus provides a new tool to improve drug delivery into the tumor.

Various strategies have been studied to endow nanosystems with stealth (Figure 2). For instance, when the proportion of hydrophilic and hydrophobic polymers is changed with negligible variation in particle size, the charges and core composition of spontaneously self-assembled micelles hindered their elimination by RES [41]. When tracked in vivo, some of these micelles accumulated less in liver, while they were more concentrated in blood at $1 \mathrm{~h}$ after intravenous injection, as compared with PEGylated micelles.

\section{Synthesis of Superparamagnetic Iron Oxide Nanoparticles}

According to the LaMer theory [42], nucleation and growth processes for the formation of uniform nanoparticulates can be divided into three phases. As the monomer concentration increases, the system accumulates energy during phase I. Once a supersaturated concentration is reached, the system has sufficient energy for a nucleation burst that will be homogeneous; hence, a narrow-size dispersed colloid is obtained. The presence of seeds such as crystallites in the medium

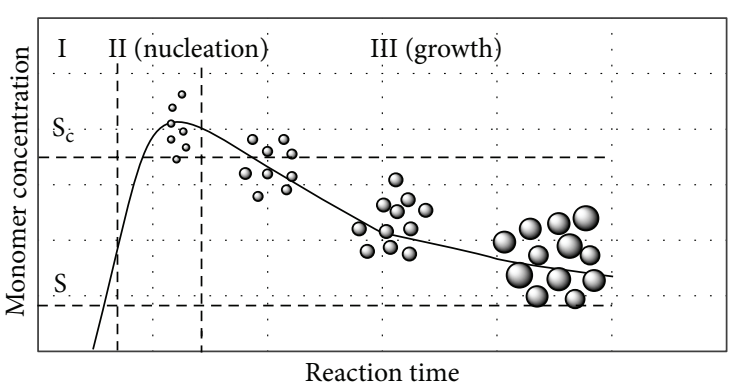

FIGURE 3: The LaMer theory describes the synthesis of monodisperse nanoparticles. $S$ and $S_{c}$ are supersaturation and critical supersaturation, respectively.

would induce heterogeneous nucleation, increasing the range of nanoparticle diameters (Figure 3).

One of the most popular chemical methods for SPION synthesis is based on coprecipitation of iron compounds [4347]. Two approaches can be used; the first takes advantage of oxidizing agents such as nitrates [43] to induce partial oxidation of ferrous hydroxide whereas the second takes place in an oxygen-free environment in which an alkaline suspension is added to an aqueous solution of ferrous $\left(\mathrm{Fe}^{2+}\right)$ and ferric $\left(\mathrm{Fe}^{3+}\right)$ ions [44]. Using the second approach, Massart obtained magnetic nanoparticles of $\sim 10 \mathrm{~nm}$ [44]. Using the first approach, however, Sugimoto et al. obtained larger magnetic nanoparticles with diameters from 30 to $200 \mathrm{~nm}$ [43]. 
Among factors affecting these methods, $\mathrm{pH}$ and ionic strength contribute the most to the efficiency and quality of the chemical reactions [43-47]. These parameters affect nanoparticle size, in turn an indicator of their dispersion stability.

Due to the properties of aqueous microdroplets that allow the confinement of growth and agglomeration processes, the microemulsion approach renders more uniform and smaller nanoparticles $[48,49]$. Assembly of surfactant-stabilized aqueous microdroplets into an oil suspension that contain iron precursors leads to controlled size SPION synthesis as the precipitation of iron oxides occurs inside the confined space [50]. Another suitable method for synthesis of uniform nanoparticles is based on polyol. When reduced in a polyol solution, metallic ions precipitate as metallic nanoparticles with size $\sim 100 \mathrm{~nm}[51,52]$. Sun et al. reported similar results when they synthesized 3 to $20 \mathrm{~nm}$-diameter monodisperse magnetic nanoparticles by thermal degradation of iron (III) acetylacetonate in phenyl ether, in the presence of alcohol, oleic acid, and oleylamine at $265^{\circ} \mathrm{C}$ [53]. Other methods are based on dendrimer platforms onto which SPION can be precipitated uniformly [54] and on the use of high-energy ultrasound waves $[55,56]$; the application of these waves induces hot empty spots that in turn randomly emit energetic waves that eventually lead to a reduction in nanoparticle size. Magnetic nanoparticles have also been synthesized by electrochemical deposition of metal on a cathode, produced by reduction of metal ions dissolved from the anode $[57,58]$, similar to polyol-based synthesis.

Emerging tools for magnetic nanoparticle synthesis use pyrolysis either by spraying a solution of $\mathrm{Fe}^{3+}$ salt and reducing agents and subsequent vaporization of the droplets obtained $[59,60]$, or by $\mathrm{CO}_{2}$ laser heating of flowing gases containing iron precursors $[61,62]$. When a critical concentration of nuclei is reached due to pressure and laser intensity, the process of homogeneous nucleation of nanoparticles begins. Iron pentacarbonyl is usually used as a precursor for synthesis of $\gamma-\mathrm{Fe}_{2} \mathrm{O}_{3}$ nanoparticles by the laser-induced pyrolysis method. Table 1 summarizes current methods for magnetic core synthesis.

2.1. SPION Functionalization. SPIONs are coated with polymers to confer colloidal suspendability. Polymers, such as hydrophilic polymers, act as stabilizers or endow nanoparticles with biocompatibility [63]. There can also be coupling of physical properties of superparamagnetic core and polymeric matrix. This coupling would depend on an external magnetic field whose power is transferred to the surrounding matrix, inducing conformational changes. The combination of magnetic nanoparticles with polymers sensitive to temperature changes induced by an external magnetic field is thus of interest [64-67].

Drug delivery systems combined with magnetic nanosystems have received constantly increasing attention (Figure 4). The possibility of summing properties increases the efficiency of drug delivery as well as the evasion of the immune system and RES. One approach that has received particular attention and effort is the magnetoliposome [65, 68-73]. Magnetic
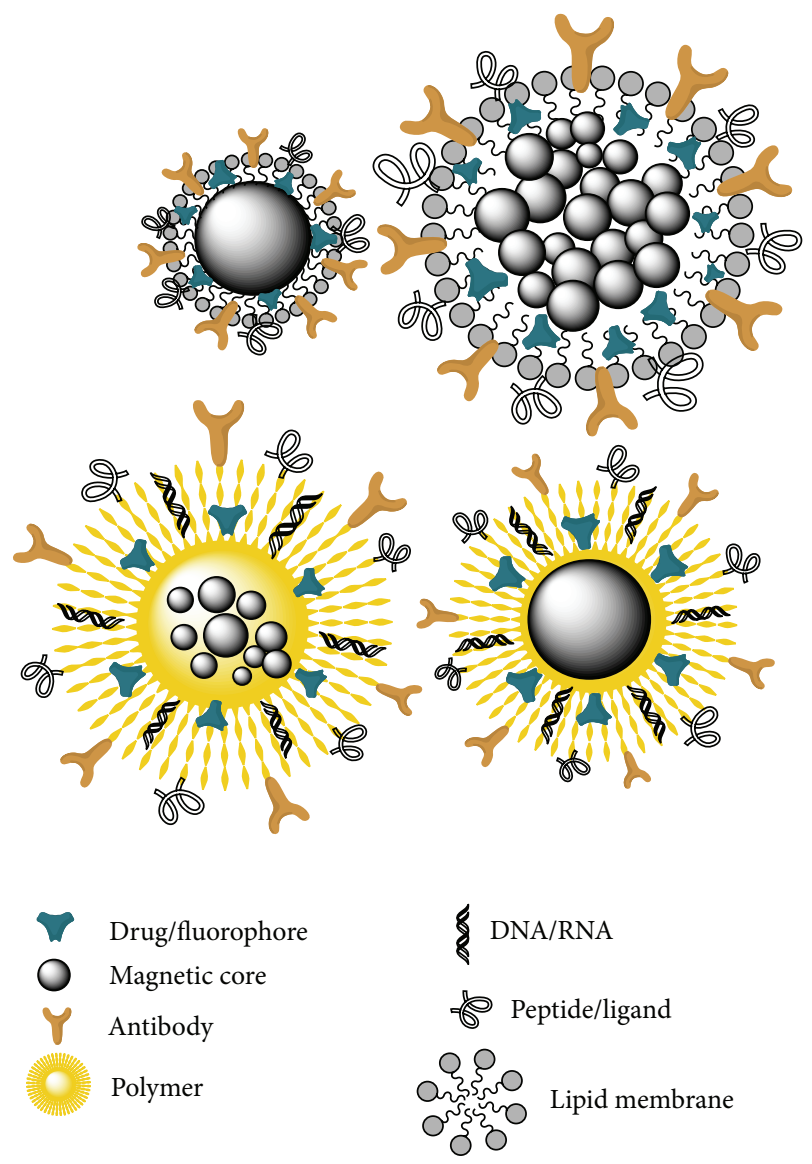

FIGURE 4: Scheme of magnetic nanoparticles based on current reports. Two main types of magnetic nanocarriers are depicted: magnetoliposomes with a lipid membrane structure surrounding either a single magnetic core or a group of them, and a biodegradable polymer encapsulating a single magnetic core or group. Hydrophilic/hydrophobic balance defines the type of drug that can be adsorbed, including genetic cargo. Molecular moieties can be attached electrostatically or covalently.

nanoparticles can be embedded in the lipid bilayer or inside the liposome, depending on the coating hydrophobicity [6873]. The former strategy might destabilize the bilayer by physical movement rather than by heat dissipation; a lower magnetic nanoparticle concentration is therefore needed to induce drug release. Nanoparticle size must be controlled to avoid further destabilization of the magnetoliposome, and an appropriate coating is mandatory. The second approach is more feasible due to the availability of hydrophilic layers, but a larger number of magnetic nanoparticles are needed to achieve the temperature increase and thus the lipid layer destabilization that leads to drug release.

Using an external magnetic field, Mikhaylov et al. showed that ferri-liposomes with SPION clusters encapsulated inside liposomes were able to reach tumor tissue in an immunocompetent tumor-bearing FVB/N mouse model [68]. Administration of the cysteine cathepsin inhibitor JPM-565 embedded in ferri-liposomes showed tumoricidal activity, as they targeted not only tumor but also stromal cells. Moreover, 
TABLE 1: Summary of synthesis methods for magnetic nanoparticles and their features.

\begin{tabular}{lcccl}
\hline Method & Temperature $\left({ }^{\circ} \mathrm{C}\right)$ & Solvent & Size range $(\mathrm{nm})$ & Morphology \\
\hline Coprecipitation & $20-90$ & Water & $15-200$ & Spherical or rhombic \\
Microemulsions & $20-50$ & Organic & $4-12$ & Spherical or cubic \\
Hydrothermal synthesis & 220 & Water-ethanol & 520 & Spherical \\
Sol-gel synthesis & $200-400$ & Organic & $20-200$ & Spherical \\
Electrochemical deposition & $70-100$ & Organic & $3-8$ & Spherical \\
Sonochemical method & 25 & Water & $10-30$ & Spherical or rod shaped \\
Polyol method & $120-280$ & Organic & $5-40$ & Spherical \\
Thermal decomposition & $100-320$ & Organic & $3-20$ & Spherical \\
Spray pyrolysis & $400-700$ & Organic & $5-60$ & Spherical but aggregated \\
Laser-induced pyrolysis & 1100 & Organic & $5-30$ & Spherical less large \\
Biomimetic synthesis & & - & $50-100$ & Spherical cluster, cubo-octahedral \\
\hline
\end{tabular}

better MRI sensitivity was observed, indicating another function of these ferri-liposomes.

In another approach, the ability of iron oxide to dissipate heat locally after exposure to an alternating magnetic field was combined with the cargo-carrying property of liposomes [74]. A distinct concept was tested in which magnetic nanoparticles were not inside the liposome, but embedded side by side in a calcium alginate hydrogel microparticle for temperature-controlled drug release.

To design an early diagnostic method and targeted therapy for pancreatic cancer, Deng et al. obtained ultrasmall superparamagnetic iron oxide nanoparticles onto which doxorubicin and antimesothelin antibody were inserted [75]. By targeting mesothelin-overexpressing pancreatic tumors, these nanoparticles showed not only correct resonance contrast but also specific targeting in two models. Dimercaptosuccinic acid (DMSA)-coated magnetic nanoparticles have likewise been tested for their ability to absorb IFN- $\gamma$ [76] and their therapeutic efficiency in tumor immunotherapy. These nanoparticles functioned correctly as an MRI agent [77] and also markedly reduced tumor growth in a mouse pancreatic tumor model (Pan02) [78]. IFN- $\gamma$ attachment to the nanocarriers did not affect its function, as different immune cell subsets such as $\mathrm{T}$ cells and macrophages were detected in tumor niches.

Although a variety of functionalization methods have been studied thoroughly, a general methodology can be followed and materials used in the processes will depend on the aim of the nanosystem. Most magnetic nanosystems are coated with a layer that supplies the magnetic core with a biocompatible, modifiable platform. If the goal is to use the nanosystem as a diagnostic agent, for instance in MRI, no other chemical processes will be needed, although further modifications can be used to increase SPION ability to avoid the RES.

Current and future perspectives address not only specific targeting of nanosystems to tumor tissue but also transport and controlled release of cargo; additionally, more complex chemical modifications have been exploited to achieve these goals. Some of these alterations include electrostatic or covalent insertion of molecules. The chemical process basically involves three types: direct conjugation, often used to conjugate drugs or fluorescent molecules (Figure 5) [7981]; linker-mediated conjugation, which is suitable for ligand attachment (Figure 6) [82-86]; and physical interactionmediated adsorption, best for assembling therapeutics such as siRNA onto nanoparticle surfaces (Figure 7) [87-89]. Other methods can also be used, such as click chemistry $[90,91]$ and hybridization $[92,93]$.

2.1.1. Making SPIONs Feasible for Gene Therapy. In addition to the superparamagnetic features of SPION, other key properties must be present in the nanocarrier for correct cargo delivery. For further conjugation, polymers must endow SPION with reactivity to nucleic acids. This reactivity might be based on physical interaction, that is, electrostatic forces, or on reactive residues through which polymer and nucleic acid react. Polymers onto which DNA or RNA will be encapsulated must have a positive surface charge for the electrostatic conjugation of nucleic acids; alternatively, both polymer and nucleic acid must be modified with reactive chemical residues for covalent conjugation. Although both strategies have been used, the former is preferred, as it does not modify nucleic acid integrity.

Once DNA/RNA is encapsulated onto SPION, the complex must assure cargo stability and integrity. Nucleic acids are very labile in the bloodstream and tissue microenvironment, due to nucleases that recognize the 2-hydroxyl residue of the sugar ring and catalyze alkaline hydrolysis [94]. Cell uptake also plays a pivotal role in DNA elimination, for example, in liver endothelial cells [95]. In addition, the encapsulation must hamper TLR7/8 recognition of DNA/RNA [96, 97] to avoid an immune response to nanocarriers, leading to early elimination from circulation.

Once at the tumor site, nanoparticles must be able to permeate the tumor matrix. Polymers used for gene cargo should protect nucleic acid from the acid microenvironment that frequently surrounds tumor tissues. Tumor cells must subsequently take up most of the nanocarriers that, once internalized, must evade lysosomal degradation to deliver the cargo into the cytosol.

Current problems with gene therapy in cancer are associated with poor expression of the therapeutic agent, due to 
Direct conjugation

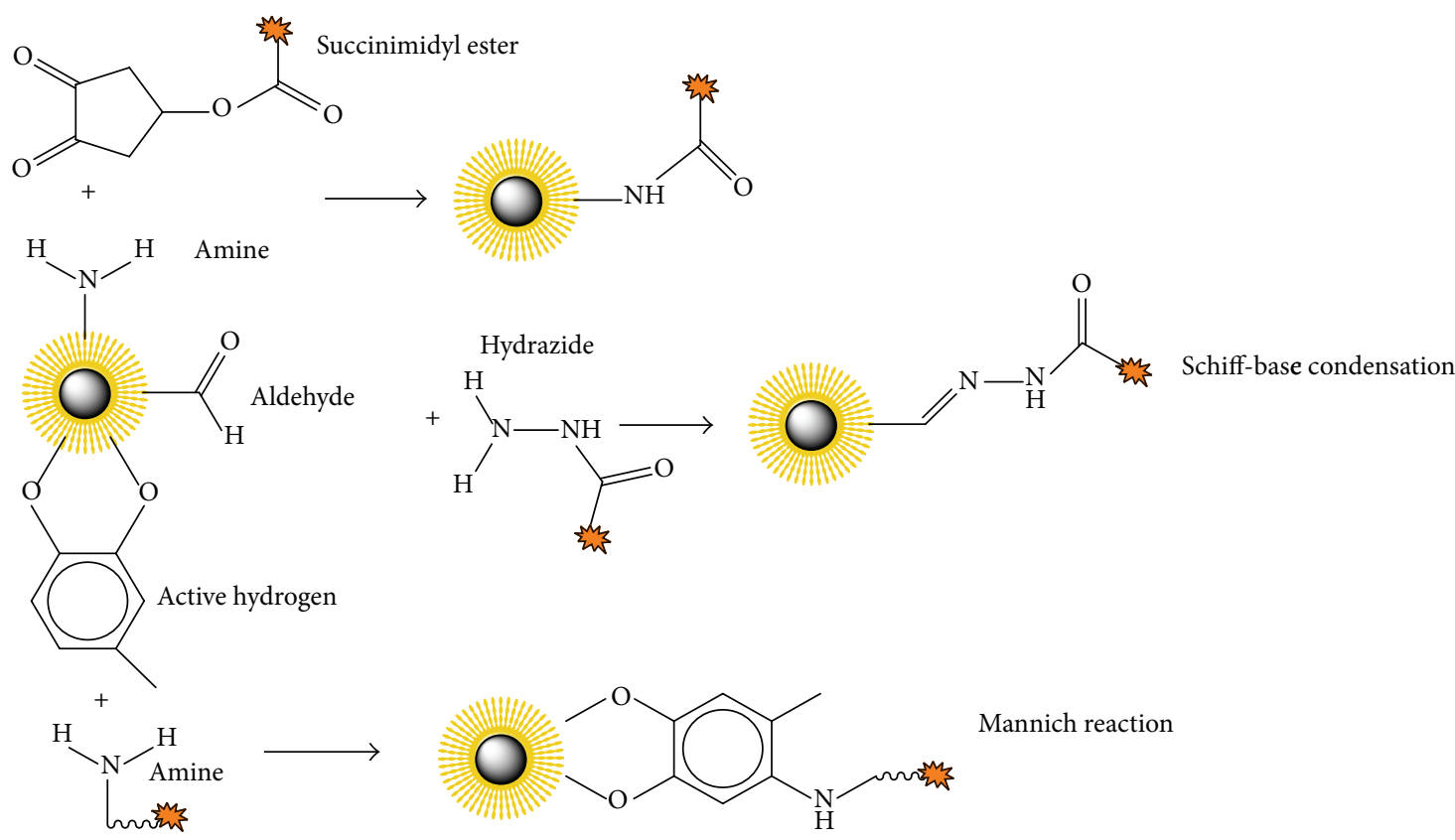

FIGURE 5: Representation of direct conjugation synthesis.

\footnotetext{
Linker-mediated conjugates
}

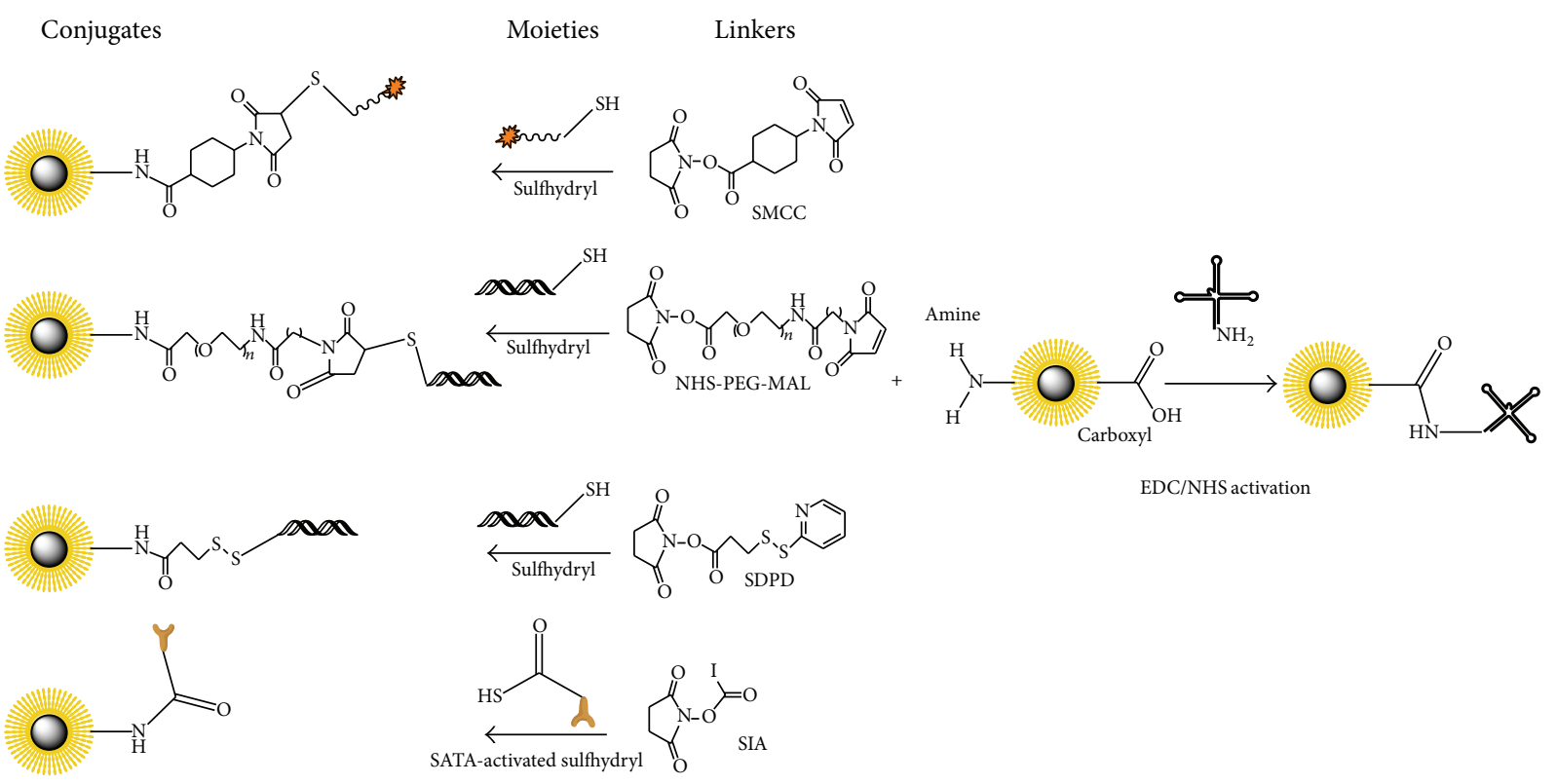

FIGURE 6: Representation of indirect conjugation through linkers.

all of the biological barriers mentioned. A variety of polymers has been developed for use in gene therapy, in which chemical modification often leads to increased gene transfection both in vitro and in in vivo models.

Polyethylenimine (PEI), one of the most popular polycations for gene transfection, has been modified with the amino acids arginine (Arg), lysine (Lys), and leucine (Leu) [98].
Intravenous administration of these modified PEI complexed with a $\beta$-galactosidase expression vector improved gene expression efficiency by threefold compared with the unmodified PEI polyplex. In another report, although the oligo (benzylethylenimine)-b-polyethylenimine (OBzEIPEI) DNA complex profile was similar to its linear PEI counterpart, OBzEI-PEI showed higher gene transfection 
Physical interaction
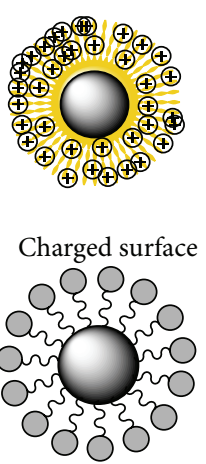

Hydrophobic interphase

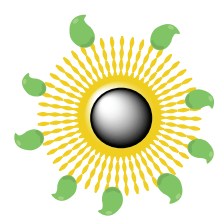

Streptavidin-functionalized surface
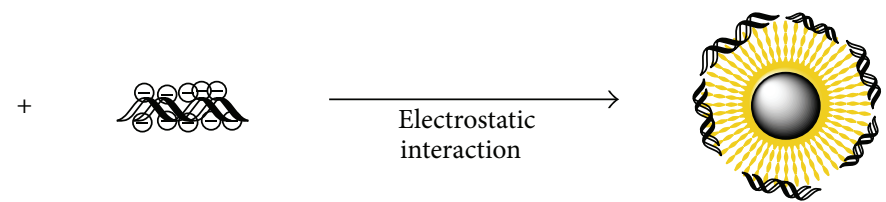

DNA/RNA
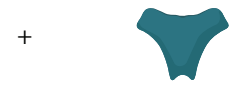

Hydrophobic interaction
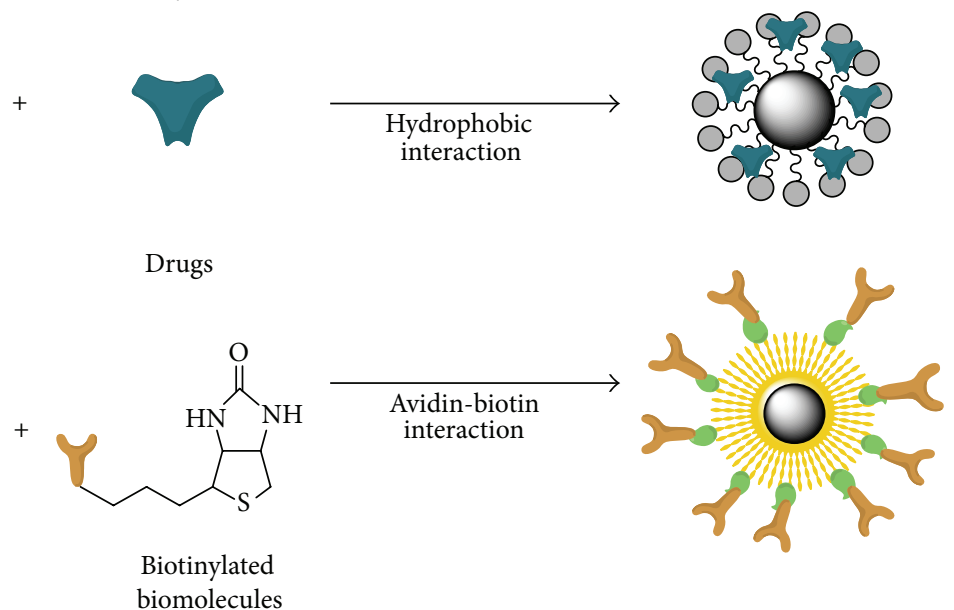

FIGURE 7: Representation of physical interactions.

efficiency in several cell lines despite decreased cell uptake of plasmid [99]; the OBz-EI moiety also contributes to the sponge effect of PEI, mediated by the $\mathrm{pH}$-sensitive membrane-disrupting activity.

In an attempt to elucidate the effect of the hydrophilic/ hydrophobic balance in PEI on function, Fan et al. reported that transfection of HeLa cells with copolymers of different degrees of hydrophobicity showed that Pluronic addition enhances gene expression [100]. This effect is apparently associated with homogeneous plasmid distribution in the cytoplasm due to the greater hydrophilic/hydrophobic ratio of Pluronics; in contrast, a lower ratio promoted nuclear localization.

Linear PEI appears able to transfect cells efficiently in vitro and in vivo. Goyal et al. synthesized a set of linear PEI nanoparticles (IPEI, $25 \mathrm{kDa}$ ) by varying the percentage of the crosslinker 1,4-butanediol diglycidyl ether (BDE) [101]. Compared with linear PEI and other available transfection agents, all BDE-crosslinked linear PEI showed higher transfection efficiency in terms of specific siRNA silencing of GFP (Green Flourescent Protein). Although both polymers, $25 \mathrm{kDa}$ branched PEI (b-PEI) and $22 \mathrm{kDa}$ linear PEI (1-PEI), are able to package DNA and siRNA, there are important differences between them. First, the b-PEI/DNA complex is less efficient than its 1-PEI/DNA counterpart in the transfection of the luciferase gene. Whereas the bPEI/siRNA complex induces gene knockdown, the 1-PEI/siRNA silencing effect is negligible [102], presumably due to poor stability of the complexes.

In addition to the sponge effect of PEI, its combination with other moieties that add new or enhanced properties to complex has been exploited exhaustively. One goal of such a strategy is to integrate gene therapy with other current therapeutics. When ataxin-1 siRNA, in complex with PEGylated chitosan modified with the cell membrane-penetrating peptide TAT, was delivered in vitro to neurodegerative spinocerebellar ataxia (SCA1) cell cultures, ataxin-1 was downmodulated at $48 \mathrm{~h}$ after transfection [103]. Similarly, PEI-PEG (polyethylene glycol) copolymers modified with the TAT peptide and loaded with doxorubicin not only packaged DNA but also delivered doxorubicin after acid cleavage and penetrated the cell membrane, mediated by TAT [104]. Adsorption of sulfamerazine (SA)-PEG-NGR on the surface of the nanopolyplexes provided double targeting to tumor vascular endothelial cells and tumor cells.

To increase PEI/DNA complex stability, He et al. established PEI/DNA complexes with hyaluronic acid (HA), previously disulfide bond-modified or unmodified [105]. The resulting complexes not only showed less cytotoxicity but also increased transfection efficiency in HA receptor-positive HepG2 and B16F10 cell lines.

An appropriate balance of modified primary PEI amines is a key factor that affects DNA complexation, transfection, and PEI cytotoxicity. When carboxylated with bromoacetic, 6-bromohexanoic, 10-bromodecanoic, and 16bromohexadecanoic acid, the higher degree of PEI substitution or a longer alkyl chain was associated with decreased DNA binding capacity [106]; cytotoxicity decreased concomitantly and transfection efficiency increased. In another attempt to hinder the intrinsic cytotoxicity of PEI, Patnaik et al. modified b-PEI/DNA by adsorption of hexametaphosphate [107]. The resulting polyplex protected DNA from 
DNases in vitro and efficiently transfected cells, either with a GFP gene expression vector or with siRNA.

Despite its limited solubility in physiological media, the linear polysaccharide chitosan has been thoroughly studied as a gene delivery agent [108]. Toh et al. obtained succinylated chitosans that were more efficient for gene transfection compared with unmodified chitosan, with lower cytotoxicity [109]. Chitosan has also been used as a polymeric material for developing theranostic nanocarriers. $\mathrm{Na}$ et al. designed a chitosan-based nanocomposite carrying Cy5.5 and paclitaxel for live imaging and cancer treatment, respectively [110]. Theranostic nanoparticles require long-term stability in the bloodstream and rapid uptake by tumor cells [111]. Other cationic polymers used for gene transfection include HBPDEAPA 60, a biodegradable amine modified hyperbranched polyester whose transfection efficiency was studied in A549 cells [112].

EPR underlies the passive targeting of most nanocarrierbased cancer therapy although active targeting is needed to increase the efficiency of these approaches. In the development of a gene-carrier platform, some strategies for polymers feasible for gene therapy require modification with targeting moieties. Moieties such as antibody [113-115], peptides [116118], aptamers, and ligands [119] endow nanosystems with tumor specificity. Apart from the EPR phenomenon and magnetic field application in the case of magnetic nanocarriers, modification with targeting moieties consequently increases nanocarrier concentration in tumor tissue and thus the in vivo efficiency of gene therapy.

2.1.2. SPIONs as Gene Nanocarriers. The magnetic fielddependent concentration of magnetic nanocarriers in a desired site has drawn attention to their potential as gene carriers. Magnetic nanocarriers not only protect genetic cargo from degradation, but also deliver this cargo correctly into targeted cells, thus resolving some problems of gene therapy. Since magnetic nanoparticles were first proposed as a feasible nonviral transfection agent $[120,121]$, magnetofection (magnetic field-guided transfection) has been studied thoroughly in in vitro and in vivo models.

Coating magnetic nanoparticles with PEG-g-PEI copolymer rendered suitable nanocarriers for MRI function in vivo in lung and liver [122]. These nanoparticles delivered a siRNA against the CD44 variant 6, a putative marker for metastatic behavior of gastric tumors, intracellularly into the SCG-7901 cell line. Nevertheless, when tested in nude mice bearing both SCG-7901 and A375-derived tumors, PEGg-PEI-SPION/siRNA complexes were unable to infiltrate tumor tissue and thus did not contrast tumors adequately. PEG-g-PEI-SPION delivered the IL-10 gene efficiently [123]; IL-10 expression triggered by magnetofection in primary vascular cells (HUVEC) conditioned the medium to induce downmodulation of TNF- $\alpha$-triggered PAI- 1 expression in these cells. PAI-1 is responsible for some vascular pathologies such as inflammation and atherosclerosis.

Further modification of PEG-g-PEI-SPIONs by attachment of a neuroblastoma-specific ligand (GD2 single chain antibody) and BcL-2 siRNA was delivered in vitro and in vivo to the SK.N-SH human neuroblastoma cell line [124].
The downodulation of BcL-2 induced an increase in cell apoptosis rates and reduced tumor growth when the nanoparticule complex was injected subcutaneously into SK-N-SH tumor-bearing female mice.

Lee et al. developed thermally crosslinked SPION that were subsequently modified with branched PEI of $1800 \mathrm{Da}$ [125]. The p53 plasmid/PEI-coated SPION nanoplexes had a hydrodynamic diameter ranging from 100 to $130 \mathrm{~nm}$; in vitro transfection of wild-type tumor suppressor p53 suppressed tumor cell proliferation. Another report demonstrated the suitability of low molecular weight PEI for gene therapy by alkylating PEI $2 \mathrm{kDa}$ and absorbing it onto magnetic nanoparticles [126]. These nanoparticles were taken up in vitro by fluc-4T1 murine mammary cancer cells (which express luciferase), as determined by confocal laser imaging. Once injected into the tumor, alkyl-PEI $2 \mathrm{kDa}$-magnetic nanoparticles conjugated with siRNA specific for the eluciferase gene, partially silenced luciferase activity, even after a single shot. Second and third intratumor injections further decreased the luciferase activity.

An interesting approach took advantage of the unique properties of the socalled yolk-shell nanocapsules. These nanosystems are composed of a magnetic core, interstitial hollow spaces, and a shell. Zhang et al. proposed a $\mathrm{Fe}_{3} \mathrm{O}_{4}$ magnetic core and a PEI-coated fluorescent mesoporous $\mathrm{SiO}_{2}$ shell [127]. Nanoplexes obtained by attachment of $\beta$-actin siRNA to the yolk-shell nanosystems efficiently silenced $\beta$ actin in HeLa cells. In addition, the fluorescent shell allowed nanoparticle tracking simultaneously with the magnetic field-dependent guidance.

By combining minicircle $\beta$-galactosidase DNA with magnetic nanoparticles coated with a stearic acid-modified low molecular weight PEI, Gao et al. were able to target the liver [128]. As early as $3 \mathrm{~h}$ after intrabiliary infusion, accumulation of magnetic nanoparticles was evident according to $\mathrm{T}_{2}$-weighted images. Immunohistochemical analysis of $\beta$ galactosidase expression and Prussian blue staining clearly demonstrated that magnetic nanoparticles accumulated in liver tissue and efficiently induced $\beta$-galactosidase expression.

In addition to PEI, other polymers have been used extensively to coat magnetic nanoparticles. Poly(maleic anhydridealt-1-decene) modified with dimethylamino propylamine was used to coat hydrophobic magnetic nanoparticles [129]. The presence of alternating hydrophilic and hydrophobic chains provides an interface for interaction with the hydrophobic surface of magnetic nanoparticles and carboxylic residues for further conjugation of protamine, a cell-penetrating peptide. The resulting magnetic nanosystem not only was less cytotoxic compared with popular gene transfection agents such as PEI and lipofectamine but also more efficiently silenced the GFP gene in U251 cells in a serum-containing medium.

To treat adenoid cystic carcinoma, Miao et al. developed PEI-coated $\mathrm{Fe}_{3} \mathrm{O}_{4}$ nanoparticles onto which the pACTERTTRAIL plasmid, a human telomerase reverse transcription promoter-driven TRIAL expression plasmid, was adsorbed electrostatically [130]. The nanocomplex triggered TRIAL expression in SACC-83 cells in vitro and in vivo and ultimately increased the apoptosis rate. 
The commercially available magnetic nanocarrier CombiMAG was also tested for its gene delivery capacity. Kong et al. demonstrated that the magnetoplex composed of CombiMAG and IGF-1R-specific shRNA was delivered efficiently into A549 cells in vitro, with inhibition of proliferation, adhesion, and chemoresistance [131-134]. A magnetoplex CombiMAG bearing the plasmid pGFPshIGRR1 that drives the concomitant expression of green fluorescent protein and the IGF-R1-specific shRNA was injected into mice via the tail vein; as early as $48 \mathrm{~h}$ post-injection, GFP expression peaked in several organs including heart, kidney, and lung [135]. IGFR1 expression decreased as early as $48 \mathrm{~h}$ after injection, as determined by western blot of explanted tumor tissue and immunohistochemistry analysis.

An interesting approach paired magnetic nanocarriers and the ultrasound microbubble technology [136]. Lipid microbubbles were coated with PEI-attached magnetic nanoparticles and a dsRed DNA plasmid was subsequently adsorbed. In a dorsal skin-fold chamber model to visualize vessel network by intravital microscopy in BL6 mice, injection of the pdsRed/PEI-coated NPs/microbubble complex delivered the genetic cargo only when both magnetic and ultrasound forces were applied in the dorsal skin. No other vascular walls were affected, indicating precise, site-specific, and ultrasound-controlled delivery of genetic cargo through the vasculature system.

Others nanocarriers suitable for DNA/siRNA delivery were obtained by coating a magnetic core with lipoids, a cationic lipid [137]. By monitoring GFP expression or luciferase activity in luciferase siRNA-treated cells, lipoidcoated magnetic nanoparticles were found to deliver both nucleic acids. The efficiency of gene expression and siRNAmediated luciferase silencing increased greatly when an external magnetic filed was applied. Mok et al. developed a magnetic nanosystem composed of $\mathrm{pH}$-sensitive branched PEI to exploit the low $\mathrm{pH}$ normally found in the tumor microenvironment [138]. Once conjugated with the tumorspecific peptide chlorotoxin and a siRNA against GFP, the nanosystem silenced GFP; in addition, its efficiency was highly dependent on the acidic conditions surrounding tumor cells.

To silence the epidermal growth factor receptor (EGFR) in tumor-infiltrating vessels, the nanocompound LipoMag was used as carrier for EGFR-specific siRNA [139]. When tested in vivo, LipoMag complexed with EGFR siRNA reduced the tumor burden in nude mice inoculated with MKN-74 or NUGC-4 as compared with commercially available PolyMag.

An important hurdle for gene therapy is gene transfection efficiency in physiological conditions, where soluble factors can hinder appropriate delivery of the nanovector. Magnetic nanoparticles developed by physical interaction between previously polyacrylic acid-coated magnetic nanoparticles and PEI demonstrated increased gene expression in the presence of $10 \%$ fetal bovine serum when an external magnetic field was applied [140].

One emerging gene nanocarrier is derived from the combination of magnetic nanoparticles and viral agents. Tested on HEK293T cells, both heparin- and streptavidin-coated magnetic nanoparticles onto which adenovirus vectors (AVVs) were adsorbed directly or through a biotin-Ni-His link, respectively, enhanced AVV-driven GFP expression when a magnetic field was applied [141, 142]. Strikingly, a heparin-coated $\mathrm{Fe}_{3} \mathrm{O}_{4} / \mathrm{AVV}$-driven neuron growth factor (NGF) expression nanocomplex was more efficient than NGF itself in neurite elongation, as seen in the pheochromocytoma of PC12 rat adrenal medulla cells [141]. For the in vitro transfection of poorly transfectable human neuron stem cells, the AVV-His ${ }_{6}$-Ni-biotin/streptavidin magnetic nanoparticles showed enhanced internalization and gene expression compared with AVV alone [142]. Sapet et al. enhanced in vivo gene expression in rat hippocampal neuronsusing a type $5 \mathrm{AVV}$ carrying a CMV-driven GFP expression cassette associated with magnetic nanoparticles [143].

\section{Conclusions and Future Challenges}

Magnetic nanoparticle technology offers an enormous field for gene therapy, especially in cancer treatment. Finding new polymers or improving those currently available as gene carriers is the goal of scientists; the development of new synthesis methods has accelerated this process. Important questions remain to be addressed, such as the escalation of magnetic nanocarrier manufacture and cytotoxicity to attain regulatory approval. Once these two elements are resolved, clinical trials can be undertaken.

\section{Acknowledgments}

The authors thank members of the DFB and MPM labs for helpful comments and discussion and C. Mark for editorial assistance. Vladimir Mulens holds a predoctoral fellowship from the Fundación La Caixa-CNB program. Some work discussed here was partially supported by grants from the Spanish Ministry of Economy and Competitiveness (SAF2011-23639 to DFB and MAT2011-23641 and CSD2007-00010 to MPM), the Madrid Regional Government (S009/MAT1726 to MPM), the Research Network in Inflammation and Rheumatic Diseases (RIER) of the ISCIII-MSPS Cooperative Research Thematic Network program (RD08/0075/0015 to $\mathrm{DFB})$, and the Guerbet Research.

\section{References}

[1] K. A. Lowe, V. M. Chia, A. Taylor et al., "An international assessment of ovarian cancer incidence and mortality," Gynecologic Oncology, vol. 130, no. 1, pp. 107-114, 2013.

[2] D. Schottenfeld, J. L. Beebe-Dimmer, P. A. Buffler, and G. S. Omenn, "Current perspective on the global and United States cancer burden attributable to lifestyle and environmental risk factors," Annual Review of Public Health, vol. 34, pp. 97-117, 2013.

[3] J. Amaro, M. Severo, S. Vilela et al., "Patterns of breast cancer mortality trends in Europe," The Breast, vol. 22, no. 3, pp. 244253, 2013

[4] S. Walters, C. Maringe, J. Butler et al., "Breast cancer survival and stage at diagnosis in Australia, Canada, Denmark, Norway, Sweden and the UK, 2000-2007: a population-based study," British Journal of Cancer, vol. 108, no. 5, pp. 1195-1208, 2013. 
[5] J. J. Salk, E. J. Fox, and L. A. Loeb, "Mutational heterogeneity in human cancers: origin and consequences," Annual Review of Pathology, vol. 5, pp. 51-75, 2010.

[6] S. Vinayak and R. W. Carlson, "mTOR inhibitors in the treatment of breast cancer," Oncology, vol. 27, no. 1, pp. 38-44, 2013.

[7] A. L. Ho, R. K. Grewal, R. Leboeuf et al., "Selumetinibenhanced radioiodine uptake in advanced thyroid cancer," The New England Journal of Medicine, vol. 368, no. 7, pp. 623-632, 2013.

[8] E. I. Heath, J. Infante, L. D. Lewis et al., "A randomized, doubleblind, placebo-controlled study to evaluate the effect of repeated oral doses of pazopanib on cardiac conduction in patients with solid tumors," Cancer Chemotherapy and Pharmacology, vol. 71, no. 3, pp. 565-573, 2013.

[9] J. W. Welsh, R. Komaki, A. Amini et al., "Phase II trial of erlotinib plus concurrent whole-brain radiation therapy for patients with brain metastases from non-small-cell lung cancer," Journal of Clinical Oncology, vol. 31, no. 7, pp. 895-902, 2013.

[10] G. Ismael, R. Hegg, S. Muehlbauer et al., "Subcutaneous versus intravenous administration of (neo)adjuvant trastuzumab in patients with HER2-positive, clinical stage I-III breast cancer (HannaH study): a phase 3, open-label, multicentre, randomised trial," The Lancet Oncology, vol. 13, no. 9, pp. 869-878, 2012.

[11] R. Tielen, C. Verhoef, F. van Coevorden et al., "Surgical treatment of locally advanced, non-metastatic, gastrointestinal stromal tumours after treatment with imatinib," European Journal of Surgical Oncology, vol. 39, no. 2, pp. 150-155, 2013.

[12] W. Li, L. P. Xu, D. I. Zhao L et al., "Cytokine-induced killer cell therapy for advanced pancreatic adenocarcinoma: a case report and review of the literature," Oncology Letters, vol. 5, no. 4, pp. 1427-1429, 2013.

[13] V. Mulens, A. De La Torre, P. Marinello et al., "Immunogenicity and safety of a NeuGcGM3 based cancer vaccine: results from a controlled study in metastatic breast cancer patients," Human Vaccines, vol. 6, no. 9, pp. 736-744, 2010.

[14] Y. Fernández-Marrero, L. Roque-Navarro, T. Hernández et al., "A cytotoxic humanized anti-ganglioside antibody produced in a murine cell line defective of N-glycolylated-glycoconjugates," Immunobiology, vol. 216, no. 12, pp. 1239-1247, 2011.

[15] J. Chomoucka, J. Drbohlavova, D. Huska, V. Adam, R. Kizek, and J. Hubalek, "Magnetic nanoparticles and targeted drug delivering," Pharmacological Research, vol. 62, no. 2, pp. 144$149,2010$.

[16] J. Klostergaard and C. E. Seeney, "Magnetic nanovectors for drug delivery," Nanomedicine, vol. 8, pp. S37-S50, 2012.

[17] T. D. Schladt, K. Schneider, H. Schild, and W. Tremel, "Synthesis and bio-functionalization of magnetic nanoparticles for medical diagnosis and treatment," Dalton Transactions, vol. 40, no. 24, pp. 6315-6343, 2011.

[18] M. J. Ruedas-Rama, J. D. Walters, A. Orte, and E. A. H. Hall, "Fluorescent nanoparticles for intracellular sensing: a review," Analytica Chimica Acta, vol. 751, pp. 1-23, 2012.

[19] Wahajuddin and S. Arora, "Superparamagnetic iron oxide nanoparticles: magnetic nanoplatforms as drug carriers," International Journal of Nanomedicine, vol. 7, pp. 3445-3471, 2012.

[20] J. M. Vargas, E. Lima Jr., R. D. Zysler, J. G. S. Duque, E. De Biasi, and M. Knobel, "Effective anisotropy field variation of magnetite nanoparticles with size reduction," European Physical Journal B, vol. 64, no. 2, pp. 211-218, 2008.
[21] H. Koo, M. S. Huh, I.-C. Sun et al., "In vivo targeted delivery of nanoparticles for theranosis," Accounts of Chemical Research, vol. 44, no. 10, pp. 1018-1028, 2011.

[22] T. E. Mccann, N. Kosaka, B. Turkbey, M. Mitsunaga, P. L. Choyke, and H. Kobayashi, "Molecular imaging of tumor invasion and metastases: the role of MRI," NMR in Biomedicine, vol. 24, no. 6, pp. 561-568, 2011.

[23] D. A. Green, M. Durand, N. Gumpeni et al., "Role of magnetic resonance imaging in bladder cancer: current status and emerging techniques," BJU International, vol. 110, no. 10, pp. 14631470, 2012.

[24] M. Sarparanta, L. M. Bimbo, J. Rytkoänen et al., "Intravenous delivery of hydrophobin-functionalized porous silicon nanoparticles: stability, plasma protein adsorption and biodistribution," Molecular Pharmaceutics, vol. 9, no. 3, pp. 654-663, 2012.

[25] Y. Zhao, C. Wang, L. Wang et al., "A frustrating problem: accelerated blood clearance of PEGylated solid lipid nanoparticles following subcutaneous injection in rat," European Journal of Pharmaceutics and Biopharmaceutics, vol. 81, no. 3, pp. 506-513, 2012.

[26] M. Baek, H. E. Chung, J. Yu et al., "Pharmacokinetics, tissue distribution, and excretion of zinc oxide nanoparticles," International Journal of Nanomedicine, vol. 7, pp. 3081-3097, 2012.

[27] J. E. Zuckerman, C. H. J. Choi, H. Han, and M. E. Davis, "Polycation-siRNA nanoparticles can disassemble at the kidney glomerular basement membrane," Proceedings of the National Academy of Sciences of the United States of America, vol. 109, no. 8, pp. 3137-3142, 2012.

[28] B. Naeye, H. Deschout, V. Caveliers et al., "In vivo disassembly of IV administered siRNA matrix nanoparticles at the renal filtration barrier," Biomaterials, vol. 34, no. 9, pp. 2350-2358, 2013.

[29] H. S. Choi, W. Liu, P. Misra et al., "Renal clearance of quantum dots," Nature Biotechnology, vol. 25, no. 10, pp. 1165-1170, 2007.

[30] D. Venturoli and B. Rippe, "Ficoll and dextran vs. globular proteins as probes for testing glomerular permselectivity: effects of molecular size, shape, charge, and deformability," American Journal of Physiology: Renal Physiology, vol. 288, no. 4, pp. F605F613, 2005.

[31] A. T. Florence and N. Hussain, "Transcytosis of nanoparticle and dendrimer delivery systems: evolving vistas," Advanced Drug Delivery Reviews, vol. 50, supplement 1, pp. S69-S89, 2001.

[32] B. He, Z. Jia, W. Du et al., "The transport pathways of polymer nanoparticles in MDCK epithelial cells," Biomaterials, vol. 34, no. 17, pp. 4309-4326, 2013.

[33] H. Hillaireau and P. Couvreur, "Nanocarriers' entry into the cell: relevance to drug delivery," Cellular and Molecular Life Sciences, vol. 66, no. 17, pp. 2873-2896, 2009.

[34] E. Fröhlich, "The role of surface charge in cellular uptake and cytotoxicity of medical nanoparticles," International Journal of Nanomedicine, vol. 7, pp. 5577-5591, 2012.

[35] A. Lesniak, A. Salvati, M. J. Santos-Martinez, M. W. Radomski, K. A. Dawson, and C. Åberg, "Nanoparticle adhesion to the cell membrane and its effect on nanoparticle uptake efficiency," Journal of the American Chemical Society, vol. 135, no. 4, pp. 1438-1444, 2013.

[36] Z. J. Deng, M. Liang, I. Toth, M. Monteiro, and R. F. Minchin, "Plasma protein binding of positively and negatively charged polymer-coated gold nanoparticles elicits different biological responses," Nanotoxicology, vol. 7, pp. 314-322, 2013. 
[37] A. Albanese, P. S. Tang, and W. C. W. Chan, "The effect of nanoparticle size, shape, and surface chemistry on biological systems," Annual Review of Biomedical Engineering, vol. 14, pp. 1-16, 2012.

[38] H. Maeda, "Vascular permeability in cancer and infection as related to macromolecular drug delivery, with emphasis on the EPR effect for tumor-selective drug targeting," Proceedings of the Japan Academy B, vol. 88, no. 3, pp. 53-71, 2012.

[39] N. T. Kimura, S. Taniguchi, K. Aoki, and T. Baba, "Selective localization and growth of Bifidobacterium bifidum in mouse tumors following intravenous administration," Cancer Research, vol. 40, no. 6, pp. 2061-2068, 1980.

[40] A. J. Giustini, A. A. Petryk, and P. J. Hoopes, "Ionizing radiation increases systemic nanoparticle tumor accumulation," Nanomedicine, vol. 8, no. 6, pp. 818-821, 2012.

[41] H. Gao, J. Xiong, T. Cheng et al., "In vivo biodistribution of mixed shell micelles with tunable hydrophilic/hydrophobic surface," Biomacromolecules, vol. 14, no. 2, pp. 460-467, 2013.

[42] V. K. Lamer and R. H. Dinegar, "Theory, production and mechanism of formation of monodispersed hydrosols," Journal of the American Chemical Society, vol. 72, no. 11, pp. 4847-4854, 1950.

[43] T. Sugimoto and E. Matijevic, "Formation of uniform spherical magnetite particles by crystallization from ferrous hydroxide gels," Journal of Colloid and Interface Science, vol. 74, no. 1, pp. 187-193, 1980.

[44] R. Massart, "Preparation of aqueous magnetic liquids in alkaline and acidic media," IEEE Transactions on Magnetics, vol. 17, no. 2, pp. 1247-1248, 1981.

[45] S. Neveu, A. Bee, M. Robineau, and D. Talbot, "Size-selective chemical synthesis of tartrate stabilized cobalt ferrite ionic magnetic fluid," Journal of Colloid and Interface Science, vol. 255, no. 2, pp. 293-298, 2002.

[46] J. Cheon, N.-J. Kang, S.-M. Lee, J.-H. Lee, J.-H. Yoon, and S. J. Oh, "Shape evolution of single-crystalline iron oxide nanocrystals," Journal of the American Chemical Society, vol. 126, no. 7, pp. 1950-1951, 2004.

[47] Y.-W. Jun, J.-S. Choi, and J. Cheon, "Heterostructured magnetic nanoparticles: their versatility and high performance capabilities," Chemical Communications, no. 12, pp. 1203-1214, 2007.

[48] M. F. Dumont, O. N. Risset, E. S. Knowles et al., "Synthesis and size control of iron(II) hexacyanochromate(III) nanoparticles and the effect of particle size on linkage isomerism," Inorganic Chemistry, vol. 52, no. 8, pp. 4494-4501, 2013.

[49] C. Aubery, C. Solans, S. Prevost, M. Gradzielski, and M. Sanchez-Dominguez, "Microemulsions as reaction media for the synthesis of mixed oxide nanoparticles: relationships between microemulsion structure, reactivity, and nanoparticle characteristics," Langmuir, vol. 29, no. 6, pp. 1779-1789, 2013.

[50] C. Okoli, M. Sanchez-Dominguez, M. Boutonnet et al., "Comparison and functionalization study of microemulsionprepared magnetic iron oxide nanoparticles," Langmuir, vol. 28, no. 22, pp. 8479-8485, 2012.

[51] S. Chkoundali, S. Ammar, N. Jouini et al., "Nickel ferrite nanoparticles: elaboration in polyol medium via hydrolysis, and magnetic properties," Journal of Physics: Condensed Matter, vol. 16, no. 24, article 4357, 2004.

[52] Y. F. Shen, J. Tang, Z. H. Nie, Y. D. Wang, Y. Ren, and L. Zuo, "Tailoring size and structural distortion of $\mathrm{Fe}_{3} \mathrm{O}_{4}$ nanoparticles for the purification of contaminated water," Bioresource Technology, vol. 100, no. 18, pp. 4139-4146, 2009.
[53] S. Sun, H. Zeng, D. B. Robinson et al., "Monodisperse $\mathrm{MFe}_{2} \mathrm{O}_{4}$ $(\mathrm{M}=\mathrm{Fe}, \mathrm{Co}, \mathrm{Mn})$ Nanoparticles," Journal of the American Chemical Society, vol. 126, no. 1, pp. 273-279, 2004.

[54] S. K. Choi, A. Myc, J. E. Silpe et al., "Dendrimer-based multivalent vancomycin nanoplatform for targeting the drugresistant bacterial surface," ACS Nano, vol. 7, no. 1, pp. 214-228, 2013.

[55] A.-L. Morel, S. I. Nikitenko, K. Gionnet et al., "Sonochemical approach to the synthesis of $\mathrm{Fe}_{3} \mathrm{O}_{4} @ \mathrm{SiO}_{2}$ core-shell nanoparticles with tunable properties," ACS Nano, vol. 2, no. 5, pp. 847856, 2008.

[56] F. Dang, N. Enomoto, J. Hojo, and K. Enpuku, "Sonochemical synthesis of monodispersed magnetite nanoparticles by using an ethanol-water mixed solvent," Ultrasonics Sonochemistry, vol. 16, no. 5, pp. 649-654, 2009.

[57] Y. Xue, H. Chen, D. Yu et al., "Oxidizing metal ions with graphene oxide: the in situ formation of magnetic nanoparticles on self-reduced graphene sheets for multifunctional applications," Chemical Communications, vol. 47, no. 42, pp. 1168911691, 2011.

[58] D. Grumelli, C. Vericat, G. Benítez et al., "Electrochemical preparation and delivery of melanin-iron covered gold nanoparticles," ChemPhysChem, vol. 10, no. 2, pp. 370-373, 2009.

[59] T. Rudin, K. Wegner, and S. E. Pratsinis, "Uniform nanoparticles by flame-assisted spray pyrolysis (FASP) of low cost precursors," Journal of Nanoparticle Research, vol. 13, no. 7, pp. 2715-2725, 2011.

[60] W. Y. Teoh, R. Amal, and L. Mädler, "Flame spray pyrolysis: an enabling technology for nanoparticles design and fabrication," Nanoscale, vol. 2, no. 8, pp. 1324-1347, 2010.

[61] O. Bomati-Miguel, P. Tartaj, M. P. Morales et al., "Core-shell iron-iron oxide nanoparticles synthesized by laser-induced pyrolysis," Small, vol. 2, no. 12, pp. 1476-1483, 2006.

[62] I. Morjan, R. Alexandrescu, F. Dumitrache et al., "Iron OxideBased nanoparticles with different mean sizes obtained by the laser pyrolysis: structural and magnetic properties," Journal of Nanoscience and Nanotechnology, vol. 10, no. 2, pp. 1223-1234, 2010.

[63] C. Liu, P. Zhang, X. Zhai et al., "Nano-carrier for gene delivery and bioimaging based on carbon dots with PEI-passivation enhanced fluorescence," Biomaterials, vol. 33, no. 13, pp. 3604$3613,2012$.

[64] B. Koppolu, Z. Bhavsar, A. S. Wadajkar et al., "Temperaturesensitive polymer-coated magnetic nanoparticles as a potential drug delivery system for targeted therapy of thyroid cancer," Journal of Biomedical Nanotechnology, vol. 8, no. 6, pp. 983-990, 2012.

[65] K. Katagiri, Y. Imai, K. Koumoto, T. Kaiden, K. Kono, and S. Aoshima, "Magnetoresponsive on-demand release of hybrid liposomes formed from $\mathrm{Fe}_{3} \mathrm{O}_{4}$ nanoparticles and thermosensitive block copolymers," Small, vol. 7, no. 12, pp. 1683-1689, 2011.

[66] S. S. Yu, R. L. Scherer, R. A. Ortega et al., "Enzymatic- and temperature-sensitive controlled release of ultrasmall superparamagnetic iron oxides (USPIOs)," Journal of Nanobiotechnology, vol. 9, no. 1, article 7, 2011.

[67] T.-Y. Liu, S.-H. Hu, K.-H. Liu, R.-S. Shaiu, D.-M. Liu, and S.Y. Chen, "Instantaneous drug delivery of magnetic/thermally sensitive nanospheres by a high-frequency magnetic field," Langmuir, vol. 24, no. 23, pp. 13306-13311, 2008.

[68] G. Mikhaylov, U. Mikac, A. A. Magaeva et al., "Ferri-liposomes as an MRI-visible drug-delivery system for targeting tumours 
and their microenvironment," Nature Nanotechnology, vol. 6, no. 9, pp. 594-602, 2011.

[69] B. Clares, R. A. Biedma-Ortiz, E. Sáez-Fernández et al., "Nanoengineering of 5-fluorouracil-loaded magnetoliposomes for combined hyperthermia and chemotherapy against colon cancer," European Journal of Pharmaceutics and Biopharmaceutics, 2013.

[70] M. R. Faria, M. M. Cruz, M. C. Gonçalves, A. Carvalho, G. Feio, and M. B. F. Martins, "Synthesis and characterization of magnetoliposomes for MRI contrast enhancement," International Journal of Pharmaceutics, vol. 446, no. 1-2, pp. 183-190, 2013.

[71] D. Qiu and X. An, "Controllable release from magnetoliposomes by magnetic stimulation and thermal stimulation," Colloids Surfaces B, vol. 104, pp. 326-329, 2013.

[72] S. García-Jimeno, E. Escribano, J. Queralt, and J. Estelrich, "External magnetic field-induced selective biodistribution of magnetoliposomes in mice," Nanoscale Research Letters, vol. 7, no. 1, article 452, 2012.

[73] B. Garnier, S. Tan, S. Miraux, E. Bled, and A. R. Brisson, "Optimized synthesis of $100 \mathrm{~nm}$ diameter magnetoliposomes with high content of maghemite particles and high MRI effect," Contrast Media and Molecular Imaging, vol. 7, no. 2, pp. 231-239, 2012.

[74] J. Hanuš, M. Ullrich, J. Dohnal, M. Singh, and F. Stěpánek, "Remotely controlled diffusion from magnetic liposome microgels," Langmuir, vol. 29, no. 13, pp. 4381-4387, 2013.

[75] L. Deng, X. Ke, Z. He et al., "A MSLN-targeted multifunctional nanoimmunoliposome for MRI and targeting therapy in pancreatic cancer," International Journal of Nanomedicine, vol. 7, pp. 5053-5065, 2012.

[76] R. Mejías, R. Costo, A. G. Roca et al., "Cytokine adsorption/release on uniform magnetic nanoparticles for localized drug delivery," Journal of Controlled Release, vol. 130, no. 2, pp. 168-174, 2008.

[77] R. Mejías, S. Pérez-Yagüe, A. G. Roca et al., "Liver and brain imaging through dimercaptosuccinic acid-coated iron oxide nanoparticles," Nanomedicine, vol. 5, no. 3, pp. 397-408, 2010.

[78] R. Mejías, S. Pérez-Yagüe, L. Gutiérrez et al., "Dimercaptosuccinic acid-coated magnetite nanoparticles for magnetically guided in vivo delivery of interferon gamma for cancer immunotherapy," Biomaterials, vol. 32, no. 11, pp. 2938-2952, 2011.

[79] Y. Gu, P. Song, T. Li, and W. Sui, "Synthesis and characterization of carboxymethyl-polyaminate chitosan and its adsorption behavior toward a reactive dye," Carbohydrate Research, vol. 346, no. 6, pp. 769-774, 2011.

[80] H. Lee, K. Y. Mi, S. Park et al., “Thermally cross-linked superparamagnetic iron oxide nanoparticles: synthesis and application as a dual imaging probe for cancer in vivo," Journal of the American Chemical Society, vol. 129, no. 42, pp. 1273912745, 2007.

[81] J. Xie, K. Chen, H.-Y. Lee et al., "Ultrasmall c(RGDyK)-coated $\mathrm{Fe}_{3} \mathrm{O}_{4}$ nanoparticles and their specific targeting to integrin $\alpha \mathrm{v} \beta 3$-rich tumor cells," Journal of the American Chemical Society, vol. 130, no. 24, pp. 7542-7543, 2008.

[82] F. Bettio, M. Canevari, C. Marzano et al., "Synthesis and biological in vitro evaluation of novel PEG-psoralen conjugates," Biomacromolecules, vol. 7, no. 12, pp. 3534-3541, 2006.

[83] L. Yuan, W. Chen, J. Hu, J. Z. Zhang, and D. Yang, "Mechanistic study of the covalent loading of paclitaxel via disulfide linkers for controlled drug release," Langmuir, vol. 29, no. 2, pp. 734743, 2013
[84] J. K. Eby, K. Y. Dane, C. P. O’Neil, S. Hirosue, M. A. Swartz, and J. Hubbell, "Polymer micelles with pyridyl disulfide-coupled antigen travel through lymphatics and show enhanced cellular responses following immunization," Acta Biomaterialia, vol. 8, no. 9, pp. 3210-3217, 2012.

[85] W. Xiao, J. Lin, M. Li et al., "Prolonged in vivo circulation time by zwitterionic modification of magnetite nanoparticles for blood pool contrast agents," Contrast Media and Molecular Imaging, vol. 7, no. 3, pp. 320-327, 2012.

[86] J. Guo, X. Gao, L. Su et al., "Aptamer-functionalized PEGPLGA nanoparticles for enhanced anti-glioma drug delivery," Biomaterials, vol. 32, no. 31, pp. 8010-8020, 2011.

[87] H. Ando, A. Okamoto, M. Yokota et al., "Development of miR92a delivery system for antiangiogenesis-based cancer therapy," The Journal of Gene Medicine, vol. 15, no. 1, pp. 20-27, 2012.

[88] S. K. Tripathi, R. Goyal, P. Kumar, and K. C. Gupta, "Linear polyethylenimine-graft-chitosan copolymers as efficient DNA/siRNA delivery vectors in vitro and in vivo," Nanomedicine, vol. 8, no. 3, pp. 337-345, 2012.

[89] Y. Bai, F. Feng, L. Zhao et al., "Aptamer/thrombin/aptamerAuNPs sandwich enhanced surface plasmon resonance sensor for the detection of subnanomolar thrombin," Biosensors Bioelectronics, vol. 47, pp. 265-270, 2013.

[90] W. G. Lewis, L. G. Green, F. Grynszpan et al., "Click chemistry in situ: acetylcholinesterase as a reaction vessel for the selective assembly of a femtomolar inhibitor from an array of building blocks," Angewandte Chemie, vol. 41, no. 6, pp. 1053-1057, 2002.

[91] G. Von Maltzahn, Y. Ren, J.-H. Park et al., "In vivo tumor cell targeting with "click" nanoparticles," Bioconjugate Chemistry, vol. 19, no. 8, pp. 1570-1578, 2008.

[92] T. C. Chu, F. Shieh, L. A. Lavery et al., "Labeling tumor cells with fluorescent nanocrystal-aptamer bioconjugates," Biosensors and Bioelectronics, vol. 21, no. 10, pp. 1859-1866, 2006.

[93] D. J. Javier, N. Nitin, M. Levy, A. Ellington, and R. RichardsKortum, "Aptamer-targeted gold nanoparticles as molecularspecific contrast agents for reflectance imaging," Bioconjugate Chemistry, vol. 19, no. 6, pp. 1309-1312, 2008.

[94] W. Yang, "Nucleases: diversity of structure, function and mechanism," Quarterly Reviews of Biophysics, vol. 44, no. 1, pp. 1-93, 2011.

[95] F. Liu, L. M. Shollenberger, C. C. Conwell, X. Yuan, and L. Huang, "Mechanism of naked DNA clearance after intravenous injection," Journal of Gene Medicine, vol. 9, no. 7, pp. 613-619, 2007.

[96] S. T. Sarvestani, B. R. G. Williams, and M. P. Gantier, "Human Toll-like receptor 8 can be cool too: implications for foreign RNA sensing," Journal of Interferon \& Cytokine Research, vol. 32, no. 8, pp. 350-361, 2012.

[97] V. Gosu, S. Basith, O. P. Kwon, and S. Choi, "Therapeutic applications of nucleic acids and their analogues in Toll-like receptor signaling," Molecules, vol. 17, no. 11, pp. 13503-13529, 2012.

[98] H. Aldawsari, B. S. Raj, R. Edrada-Ebel et al., "Enhanced gene expression in tumors after intravenous administration of arginine-, lysine- and leucine-bearing polyethylenimine polyplex," Nanomedicine, vol. 7, no. 5, pp. 615-623, 2011.

[99] C. Chandrashekhar, B. Pons, C. D. Muller, N. Tounsi, R. Mulherkar, and G. Zuber, "Oligobenzylethylenimine enriches linear polyethylenimine with a $\mathrm{pH}$-sensitive membrane-disruptive property and leads to enhanced gene delivery activity," Acta Biomaterialia, vol. 9, no. 2, pp. 4985-4993, 2012. 
[100] W. Fan, X. Wu, B. Ding et al., "Degradable gene delivery systems based on Pluronics-modified low-molecular-weight polyethylenimine: preparation, characterization, intracellular trafficking, and cellular distribution," International Journal of Nanomedicine, vol. 7, pp. 1127-1138, 2012.

[101] R. Goyal, S. K. Tripathi, S. Tyagi et al., "Linear PEI nanoparticles: efficient pDNA/siRNA carriers in vitro and in vivo," Nanomedicine, vol. 8, no. 2, pp. 167-175, 2012.

[102] A. Kwok and S. L. Hart, "Comparative structural and functional studies of nanoparticle formulations for DNA and siRNA delivery," Nanomedicine, vol. 7, no. 2, pp. 210-219, 2011.

[103] M. Malhotra, C. Tomaro-Duchesneau, and S. Prakash, "Synthesis of TAT peptide-tagged PEGylated chitosan nanoparticles for siRNA delivery targeting neurodegenerative diseases," Biomaterials, vol. 34, no. 4, pp. 1270-1280, 2012.

[104] C. Liu, F. Liu, L. Feng, M. Li, J. Zhang, and N. Zhang, "The targeted co-delivery of DNA and doxorubicin to tumor cells via multifunctional PEI-PEG based nanoparticles," Biomaterials, vol. 34, no. 10, pp. 2547-2564, 2013.

[105] Y. He, G. Cheng, L. Xie, Y. Nie, B. He, and Z. Gu, "Polyethyleneimine/DNA polyplexes with reduction-sensitive hyaluronic acid derivatives shielding for targeted gene delivery," Biomaterials, vol. 34, no. 4, pp. 1235-1245, 2012.

[106] R. K. Oskuee, A. Dehshahri, W. T. Shier, and M. Ramezani, "Alkylcarboxylate grafting to polyethylenimine: a simple approach to producing a DNA nanocarrier with low toxicity," Journal of Gene Medicine, vol. 11, no. 10, pp. 921-932, 2009.

[107] S. Patnaik, M. Arif, A. Pathak, R. Kurupati, Y. Singh, and K. C. Gupta, "Cross-linked polyethylenimine-hexametaphosphate nanoparticles to deliver nucleic acids therapeutics," Nanomedicine, vol. 6, no. 2, pp. 344-354, 2010.

[108] M. Garcia-Fuentes and M. J. Alonso, "Chitosan-based drug nanocarriers: where do we stand?" Journal of Controlled Release, vol. 161, no. 2, pp. 496-504, 2012.

[109] E. K.-W. Toh, H.-Y. Chen, Y.-L. Lo, S.-J. Huang, and L.-F. Wang, "Succinated chitosan as a gene carrier for improved chitosan solubility and gene transfection," Nanomedicine, vol. 7, no. 2, pp. 174-183, 2011.

[110] J. H. Na, S. Y. Lee, S. Lee et al., "Effect of the stability and deformability of self-assembled glycol chitosan nanoparticles on tumor-targeting efficiency," Journal of Controlled Release, vol. 163 , no. 1, pp. 2-9, 2012.

[111] J. H. Na, H. Koo, S. Lee et al., "Real-time and non-invasive optical imaging of tumor-targeting glycol chitosan nanoparticles in various tumor models," Biomaterials, vol. 32 , no. 22, pp. 52525261, 2011.

[112] R. Reul, J. Nguyen, A. Biela et al., "Biophysical and biological investigation of DNA nano-complexes with a non-toxic, biodegradable amine-modified hyperbranched polyester," International Journal of Pharmaceutics, vol. 436, no. 1-2, pp. 97-105, 2012.

[113] M. Monaghan, U. Greiser, H. Cao, W. Wang, and A. Pandit, "An antibody fragment functionalized dendritic PEGylated poly(2(dimethylamino)ethyl diacrylate) as a vehicle of exogenous microRNA," Drug Delivery and Translational Research, vol. 2, no. 5, pp. 406-414, 2012.

[114] T. Merdan, J. Callahan, H. Petersen et al., "Pegylated polyethylenimine-Fab/ antibody fragment conjugates for targeted gene delivery to human ovarian carcinoma cells," Bioconjugate Chemistry, vol. 14, no. 5, pp. 989-996, 2003.

[115] Y. Chen, W. Wang, G. Lian et al., "Development of an MRIvisible nonviral vector for siRNA delivery targeting gastric cancer," International Journal of Nanomedicine, vol. 7, pp. 359$368,2012$.

[116] K. K. Hou, H. Pan, G. M. Lanza, and S. A. Wickline, "Melittin derived peptides for nanoparticle based siRNA transfection," Biomaterials, vol. 34, no. 12, pp. 3110-3119, 2013.

[117] G. D. Kenny, C. Villegas-Llerena, A. D. Tagalakis et al., "Multifunctional receptor-targeted nanocomplexes for magnetic resonance imaging and transfection of tumours," Biomaterials, vol. 33, no. 29, pp. 7241-7250, 2012.

[118] H. Y. Wang, W. J. Yi, S. Y. Qin, C. Li, R. X. Zhuo, and X. Z. Zhang, "Tyroserleutide-based gene vector for suppressing VEGF expression in cancer therapy," Biomaterials, vol. 33, no. 33, pp. 8685-8694, 2012.

[119] M. K. Yu, J. Park, and S. Jon, "Targeting strategies for multifunctional nanoparticles in cancer imaging and therapy," Theranostics, vol. 2, no. 1, pp. 3-44, 2012.

[120] F. Krötz, C. de Wit, H.-Y. Sohn et al., "Magnetofection-a highly efficient tool for antisense oligonucleotide delivery in vitro and in vivo," Molecular Therapy, vol. 7, no. 5, pp. 700-710, 2003.

[121] C. Plank, F. Scherer, U. Schillinger, C. Bergemann, and M. Anton, "Magnetofection: enhancing and targeting gene delivery with superparamagnetic nanoparticles and magnetic fields," Journal of Liposome Research, vol. 13, no. 1, pp. 29-32, 2003.

[122] Y. Chen, G. Lian, C. Liao et al., "Characterization of polyethylene glycol-grafted polyethylenimine and superparamagnetic iron oxide nanoparticles (PEG-g-PEI-SPION) as an MRIvisible vector for siRNA delivery in gastric cancer in vitro and in vivo," Journal of Gastroenterology, vol. 48, no. 7, pp. 809-821, 2013.

[123] R. Namgung, K. Singha, M. K. Yu et al., "Hybrid superparamagnetic iron oxide nanoparticle-branched polyethylenimine magnetoplexes for gene transfection of vascular endothelial cells," Biomaterials, vol. 31, no. 14, pp. 4204-4213, 2010.

[124] M. Shen, F. Gong, P. Pang et al., "An MRI-visible non-viral vector for targeted Bcl-2 siRNA delivery to neuroblastoma," International Journal of Nanomedicine, vol. 7, pp. 3319-3332, 2012.

[125] H. J. Lee, Y. T. C. Nguyen, M. Muthiah et al., "MR traceable delivery of p53 tumor suppressor gene by PEIfunctionalized superparamagnetic iron oxide nanoparticles," Journal of Biomedical Nanotechnology, vol. 8, no. 3, pp. 361-371, 2012.

[126] G. Liu, J. Xie, F. Zhang et al., "N-Alkyl-PEI-functionalized iron oxide nanoclusters for efficient siRNA delivery," Small, vol. 7, no. 19, pp. 2742-2749, 2011.

[127] L. Zhang, T. Wang, L. Li, C. Wang, Z. Su, and J. Li, "Multifunctional fluorescent-magnetic polyethyleneimine functionalized $\mathrm{Fe}_{3} \mathrm{O}_{4}$-mesoporous silica yolk-shell nanocapsules for siRNA delivery," Chemical Communications, vol. 48, no. 69, pp. 87068708, 2012.

[128] L. Gao, L. Xie, X. Long et al., "Efficacy of MRI visible iron oxide nanoparticles in delivering minicircle DNA into liver via intrabiliary infusion," Biomaterials, vol. 34, no. 14, pp. 3688 3696, 2013.

[129] L. Qi, L. Wu, S. Zheng, Y. Wang, H. Fu, and D. Cui, "Cellpenetrating magnetic nanoparticles for highly efficient delivery and intracellular imaging of siRNA," Biomacromolecules, vol. 13, no. 9, pp. 2723-2730, 2012.

[130] L. Miao, K. Zhang, C. Qiao et al., "Antitumor effect of human TRAIL on adenoid cystic carcinoma using magnetic nanoparticle-mediated gene expression," Nanomedicine, vol. 9, no. 1, pp. 141-150, 2013. 
[131] J. Qian, A. Dong, M. Kong, Z. Ma, J. Fan, and G. Jiang, "Suppression of type 1 insulin-like growth factor receptor expression by small interfering RNA inhibits A549 human lung cancer cell invasion in vitro and metastasis in xenograft nude mice," Acta Biochimica et Biophysica Sinica, vol. 39, no. 2, pp. 137-147, 2007.

[132] A.-Q. Dong, M.-J. Kong, Z.-Y. Ma, J.-F. Qian, and X.-H. Xu, "Down-regulation of IGF-IR using small, interfering, hairpin RNA (siRNA) inhibits growth of human lung cancer cell line A549 in vitro and in nude mice," Cell Biology International, vol. 31, no. 5, pp. 500-507, 2007.

[133] A. Dong, M. Kong, Z. Ma, J. Qian, H. Cheng, and X. Xu, "Knockdown of insulin-like growth factor 1 receptor enhances chemosensitivity to cisplatin in human lung adenocarcinoma A549 cells," Acta Biochimica et Biophysica Sinica, vol. 40, no. 6, pp. 497-504, 2008.

[134] C. Wang, C. Ding, M. Kong et al., "Tumor-targeting magnetic lipoplex delivery of short hairpin RNA suppresses IGF-1R overexpression of lung adenocarcinoma A549 cells in vitro and in vivo," Biochemical and Biophysical Research Communications, vol. 410, no. 3, pp. 537-542, 2011.

[135] M. Kong, X. Li, C. Wang et al., "Tissue distribution and cancer growth inhibition of magnetic lipoplex-delivered type 1 insulin-like growth factor receptor shRNA in nude mice," Acta Biochimica et Biophysica Sinica, vol. 44, pp. 591-596, 2012.

[136] H. Mannell, J. Pircher, F. Fochler et al., "Site directed vascular gene delivery in vivo by ultrasonic destruction of magnetic nanoparticle coated microbubbles," Nanomedicine, vol. 8, no. 8, pp. 1309-1318, 2012.

[137] S. Jiang, A. A. Eltoukhy, K. T. Love, R. Langer, and D. G. Anderson, "Lipidoid-coated iron oxide nanoparticles for efficient DNA and siRNA delivery," NanoLetters, vol. 13, no. 3, pp. 1059-1064, 2013.

[138] H. Mok, O. Veiseh, C. Fang et al., "PH-sensitive siRNA nanovector for targeted gene silencing and cytotoxic effect in cancer cells," Molecular Pharmaceutics, vol. 7, no. 6, pp. 1930-1939, 2010.

[139] Y. Namiki, T. Namiki, H. Yoshida et al., "A novel magnetic crystal-lipid nanostructure for magnetically guided in vivo gene delivery," Nature Nanotechnology, vol. 4, no. 9, pp. 598-606, 2009.

[140] S.-L. Sun, Y.-L. Lo, H.-Y. Chen, and L.-F. Wang, "Hybrid polyethylenimine and polyacrylic acid-bound iron oxide as a magnetoplex for gene delivery," Langmuir, vol. 28, no. 7, pp. 3542-3552, 2012.

[141] J.-H. Hwang, S. Lee, E. Kim et al., "Heparin-coated superparamagnetic nanoparticle-mediated adeno-associated virus delivery for enhancing cellular transduction," International Journal of Pharmaceutics, vol. 421, no. 2, pp. 397-404, 2011.

[142] E. Kim, J.-S. Oh, I.-S. Ahn, K. I. Park, and J.-H. Jang, “Magnetically enhanced adeno-associated viral vector delivery for human neural stem cell infection," Biomaterials, vol. 32, no. 33, pp. 8654-8662, 2011.

[143] C. Sapet, C. Pellegrino, N. Laurent, F. Sicard, and O. Zelphati, "Magnetic nanoparticles enhance adenovirus transduction in vitro and in vivo," Pharmaceutical Research, vol. 29, no. 5, pp. 1203-1218, 2012. 

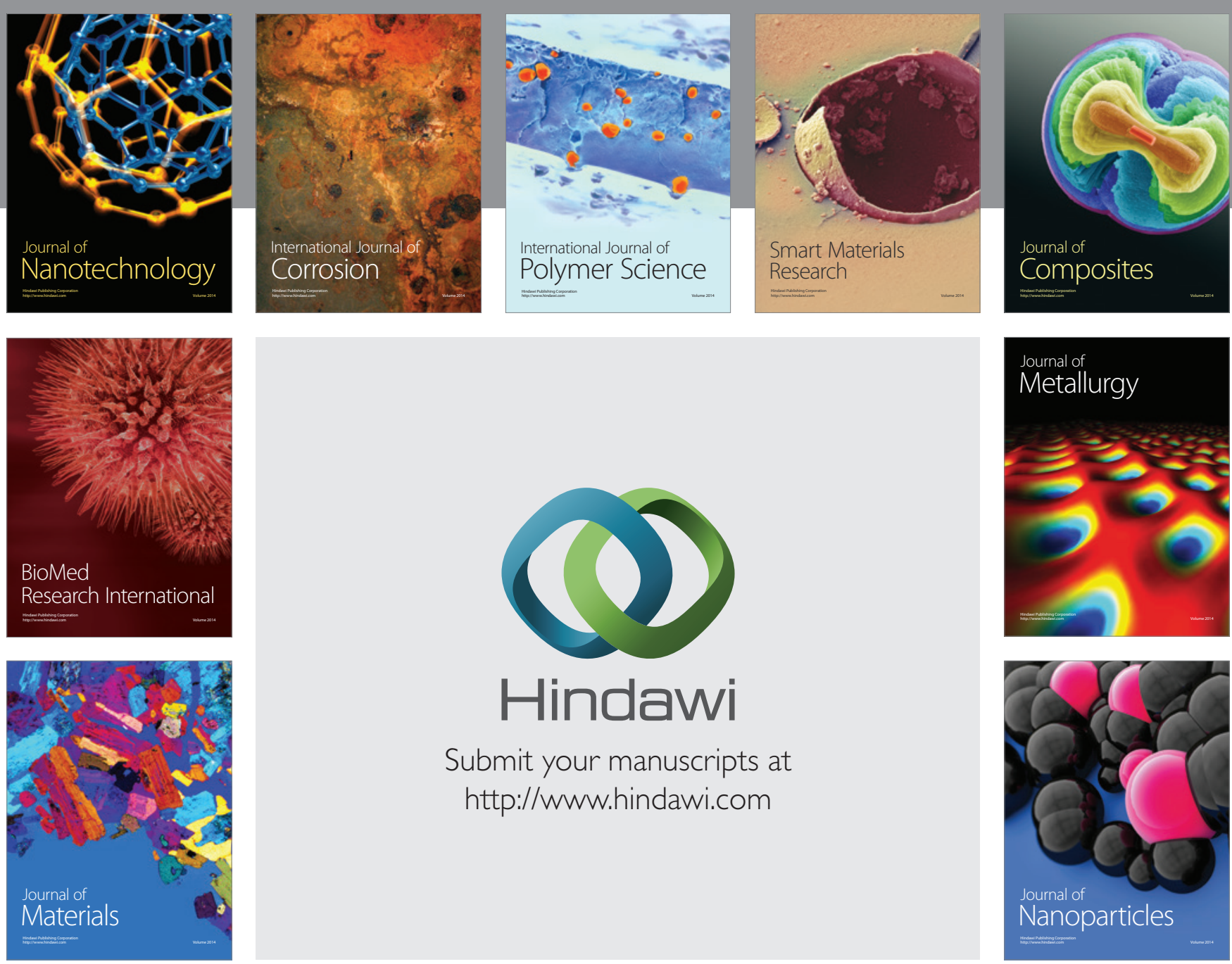

Submit your manuscripts at http://www.hindawi.com
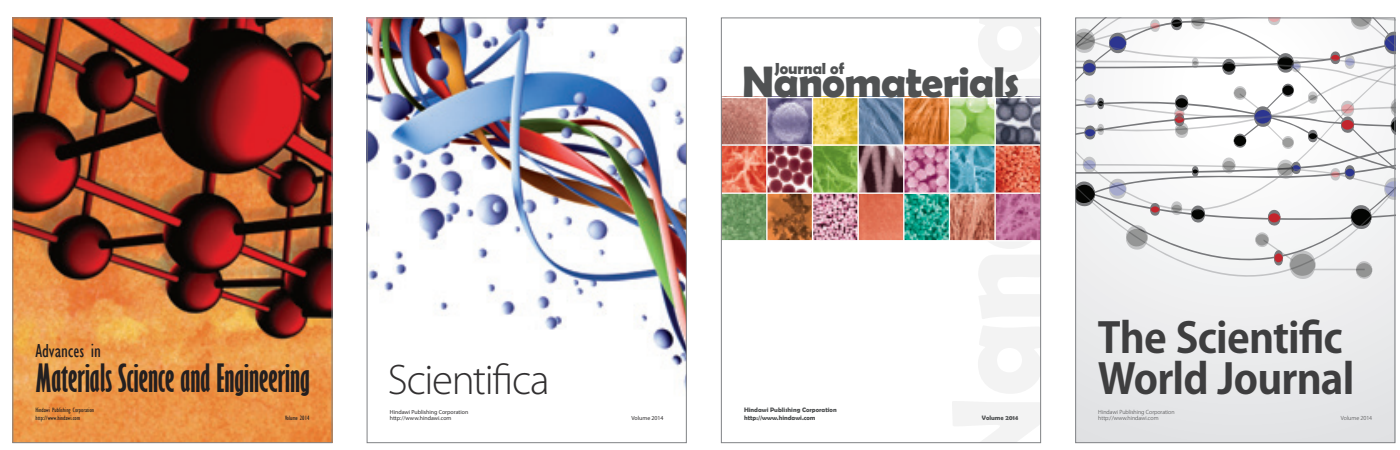

\section{The Scientific World Journal}
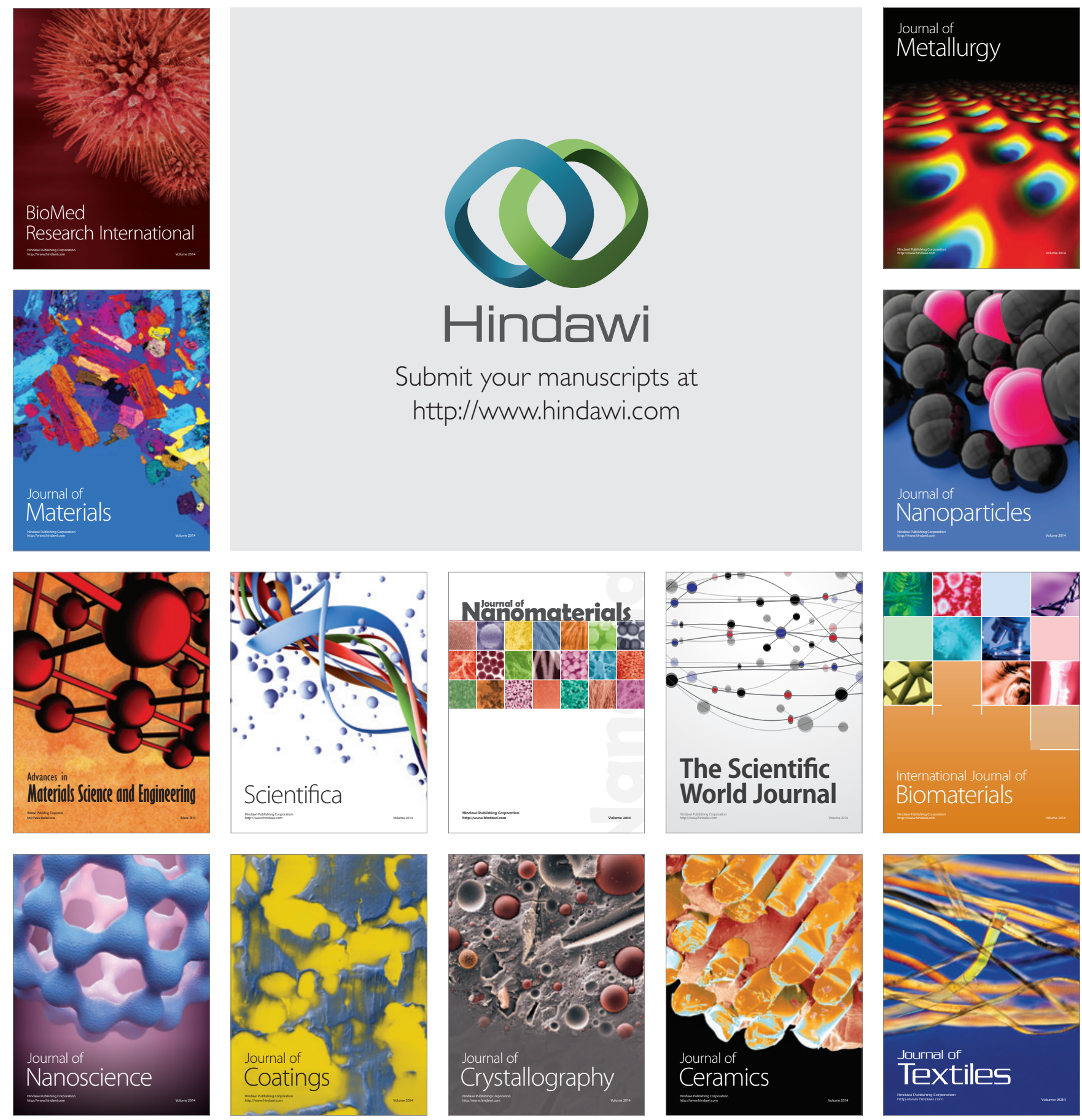